\title{
Aspectos da construção histórica da identidade da educação de jovens e adultos no Brasil e em Portugal: enfoque na agenda política e suas práticas discursivas
}

\author{
Aspects of the historical construction of the identity of youth and adult education in Brazil \\ and Portugal: focus on the political agenda and its discursive practices
}

Aspectos de la construcción histórica de la identidad de la educación de adultos en Brasil y Portugal: enfoque en la agenda política y sus prácticas discursivas

\author{
Maria Margarida Machado \\ Universidade Federal de Goiás (Brasil) \\ https://orcid.org/0000-0002-5036-4334 \\ http://lattes.cnpq.br/3133555536143694 \\ mmm2404@gmail.com \\ Rosanna Barros \\ Universidade do Algarve (Portugal) \\ http://orcid.org/0000-0002-3882-1539 \\ rosanna@net.sapo.pt
}

\section{RESUMO}

Esse artigo resulta das reflexões acerca da Educação de Jovens e Adultos (EJA) no Brasil e em Portugal, produzidas desde o ponto de vista da história e historiografia da educação. Identificamos que a identidade da EJA a nível acadêmico tem sido problemática, por um lado, devido à acentuada interdisciplinaridade do seu corpo teórico; e por outro lado, derivado também ao seu cariz fortemente direcionado para a prática e para a intervenção social, que implica um nível de atuação, participação e ingerência que não se ajusta ao tipo ideal de performance acadêmica. É neste sentido que a institucionalização acadêmica da área da EJA não representou a sua demarcação de fato enquanto disciplina autônoma, com uma identidade teórica específica, resultante de uma produção de conhecimento própria, mas constituiu, na essência, um ramo de aplicação disciplinar no âmbito geral da investigação educacional realizada. No entanto, há, uma identidade global na área da EJA que resulta da inter-relação do conjunto das suas três dimensões constituintes principais em necessária, contraditória e processual relação: o campo de práticas educativas; o campo de práticas de investigação; e o campo de práticas discursivas. Neste artigo focamo-nos, exclusivamente, no campo de práticas discursivas inerente à agenda política, e portanto, à ação do Estado a partir do advento da democracia quer no Brasil quer em Portugal.

Palavras-chave: Identidade da Educação de Jovens e Adultos. Políticas Públicas. EJA em Portugal e no Brasil período democrático. 


\begin{abstract}
This article results from the reflections about the Education of Young and Adults (EJA) in Brazil and Portugal, produced from the point of view of the history and historiography of education. We identify that the identity of the EJA at the academic level has been problematic, on the one hand, due to the accentuated interdisciplinarity of its theoretical body; and on the other hand, also due to its strong focus on practice and social intervention, which implies a level of performance, participation and interference that does not fit the ideal type of academic performance. It is in this sense that the academic institutionalization of the EJA area did not represent its demarcation de fato as an autonomous discipline, with a specific theoretical identity, resulting from a production of own knowledge, but it constituted, in essence, a branch of disciplinary application in the general scope of educational research. There is, however, a global identity in the area of EJA that results from the interrelation of the three main constituent dimensions in a necessary, contradictory and procedural relationship: the field of educational practices; the field of research practices; and the field of discursive practices. In this article, we focus exclusively on the field of discursive practices inherent in the political agenda, and therefore, on the action of the State from the advent of democracy in Brazil and Portugal.
\end{abstract}

Keywords: Identity of Youth and Adult Education. Public policy. EJA in Portugal and in Brazil democratic period.

\title{
RESUMEN
}

Este artículo es el resultado de reflexiones sobre la Educación de Jóvenes y Adultos (EJA) en Brasil y Portugal, producidos desde el punto de vista de la historia y la historiografía de la educación. Identificamos que la identidad de la EJA a nivel académico ha sido problemática, por un lado, debido a la acentuada interdisciplinaridad de su cuerpo teórico; y por otro lado, derivado también a su cariz fuertemente dirigido hacia la práctica y para la intervención social, que implica un nivel de actuación, participación e injerencia que no se ajusta al tipo ideal de desempeño académico. En este sentido, la institucionalización académica del área de la EJA no representó su demarcación de hecho como disciplina autónoma, con una identidad teórica específica, resultante de una producción de conocimiento propia, sino que constituyó, en esencia, una rama de aplicación disciplinaria en el ámbito general de la investigación educativa realizada. Sin embargo, hay, una identidad global en el área de la EJA que resulta de la interrelación del conjunto de sus tres dimensiones constituyentes principales en necesaria, contradictoria y procesal relación: el campo de prácticas educativas; el campo de las prácticas de investigación; y el campo de prácticas discursivas. En este artículo nos centramos exclusivamente en el campo de las prácticas discursivas inherentes a la agenda política, y por lo tanto la acción del estado desde el advenimiento de la democracia, ya sea en Brasil o en Portugal.

Palabras clave: Identidad de la Educación de Jóvenes y Adultos; Políticas públicas; EJA en Portugal y Brasil periodo democrático. 


\section{Introdução}

A educação de jovens e adultos (EJA) enquanto área temática do conhecimento científico produzido no ocidente foi conquistando gradualmente um estatuto próprio que lhe permitiu ocupar um espaço acadêmico ao nível das instituições universitárias e respetivos centros de investigação, especialmente no âmbito das faculdades e dos departamentos de educação. Porém, o processo através do qual ocorre este reconhecimento no plano científico não tem sido nem pacífico nem linear, conhecendo diversos graus de implementação na academia, consoante o grau de conservadorismo teórico-conceitual prevalecente nas diversas instituições e a maior ou menor tradição teórico pedagógica existente nos vários contextos nacionais. Olesen refere a este propósito que a nível geral "até recentemente, as instituições acadêmicas não estavam muito envolvidas na educação de adultos, a não ser apenas como uma simples especialidade dos departamentos de educação/pedagogia (...) por vezes, as relações entre ambas eram até mesmo hostis" (2003, p. 30).

Esta institucionalização da EJA, apesar de progressiva e em muitos contextos nacionais algo descontínua, permitiu, contudo, a consolidação de uma comunidade científica internacional de referência na área. Verificando-se inclusive que o campo da EJA conheceu uma crescente visibilidade dentro do saber produzido pela academia, consubstanciado, quer pelos círculos de intercâmbio científicos habituais, tais como a promoção de colóquios e congressos especializados nesta matéria ou a criação e maior visibilidade em associações científicas da área ${ }^{1}$; quer pelas práticas letivas e de investigação nas universidades, institutos e politécnicos, que passam pela oferta de cursos de licenciatura e de pós-graduação, pela publicação de numerosas revistas especializadas de grande prestígio e difusão ${ }^{2}$, ou pela significativa produção ensaística e investigativa de fato existente.

Historicamente com o desenvolvimento das ciências sociais modernas, o século dezenove representa, na história do pensamento científico, o século da institucionalização e profissionalização dos saberes disciplinares. Sem surpresa, e à semelhança do que ocorreu noutros domínios, também a área da EJA ir-se-ia profissionalizar, tornando-se formalmente desde então um campo ou subsistema de educação, que hoje conhecemos com escolas, coordenações e departamentos oficiais e professores profissionais a coexistir com contextos educacionais mais informais, de carácter comunitário, nos quais predominam os educadores voluntários e diversos promotores de movimentos sociais. A principal consequência que daqui advém é, especialmente, uma maior consolidação do campo a nível acadêmico, na medida em que aumentou a necessidade de construir um saber especializado para permitir qualificar novos profissionais para o setor, bem como para atualizar e dinamizar os conhecimentos dos educadores de jovens e adultos não profissionalizados.

Contudo, a identidade da EJA a nível acadêmico tem sido problemática, por um lado, devido à acentuada interdisciplinaridade que caracteriza o seu corpo teórico, e na medida em que se trata, na sua essência, de uma área subsidiária de outras disciplinas, a EJA nunca chegará a ser verdadeiramente reconhecida pela tradição acadêmica; e por outro lado, derivado também ao seu cariz fortemente direcionado para a prática e para a intervenção social, que implica um nível de atuação, participação e ingerência que não se ajusta ao tipo ideal de performance acadêmica, o que, por seu turno, contribuiu frequentemente para distanciar os educadores de adultos dos circuitos mais acadêmicos (OLESEN, 2003). É neste sentido que a institucionalização acadêmica da área da EJA não representou a sua demarcação de fato enquanto disciplina autônoma, com uma identidade teórica específica, resultante de

\footnotetext{
${ }^{1}$ Veja-se na Europa o caso da European Society for Research on the Education of Adults (ESREA): https://www.esrea.org/.

${ }^{2}$ De que são exemplos: i) Adult Education Quarterly (AEQ); ii) European Journal for Research on the Education and Learning of Adults (RELA); iii) Studies in the Education of Adults (SEA); etc.
} 
uma produção de conhecimento própria, mas constituiu, na essência, um ramo de aplicação disciplinar no âmbito geral da investigação educacional realizada, na maior parte das vezes, por sociólogos ou antropólogos da educação, por filósofos e historiadores da educação, por pedagogos e economistas, ou por outros investigadores inscritos nas ciências sociais.

No entanto, parece-nos que há, claramente, uma identidade global na área da EJA que resulta da inter-relação do conjunto das suas três dimensões constituintes principais, que representam no nosso entender, três polaridades dialéticas em necessária, contraditória e processual relação: o campo de práticas educativas; o campo de práticas de investigação; e o campo de práticas discursivas. Assim, a identidade da EJA processa-se na interligação, no movimento, na dialética entre o que de mais significativo ocorre em cada um destes campos interdependentes.

Contrariamente ao que tem sido defendido como especificidade e demarcação metodológica inerente à maioria das práticas educativas do setor, o seu corpus teórico tem sido usualmente criticado por não representar uma integração própria de contributos disciplinares nem se apresentar como uma delimitação suficientemente consolidada em relação às disciplinas que lhe dão origem, como salienta Stock, "esta teoria é particularmente fragmentada ou até mesmo repartida por várias disciplinas acadêmicas que satisfazem o estudo da educação para adultos" (STOCK, 1996, p. 21). Com frequência as suas formulações teóricas estão inscritas no quadro geral das ciências da educação, com todas as implicações epistemológicas que este fato acarreta quando analisado num nível mais aprofundado de abstração analítica que prefere traçar fronteiras teórico-conceituais, como é, de resto, caraterístico do modo moderno de produção de conhecimento científico.

A identidade teórica da educação de adultos advém assim, sobretudo, da sobreposição dos principais contributos teóricos que emanam de distintos saberes disciplinares e que, no fundo, são os que emolduram e dão sentido ao mapa conceptual usado no setor (BRIGHT, 1989). As práticas discursivas, por seu turno, se derivam em boa medida desta moldura epistemológica, também são profundamente modeladas pela agenda das políticas públicas que lhe conferem significações exteriores, e frequentemente persuasivas, que complexificam a construção de identidade neste setor. Ora, neste artigo escolhemos focar-nos exclusivamente no campo de práticas discursivas inerente à agenda política, e portanto, à ação do Estado a partir do advento da Democracia no Brasil e em Portugal. No caso do Brasil, essa prática política será analisada com base na regulamentação federal resultante dos processos pósabertura democrática com o final da Ditadura Civil Militar, em 1985, principalmente a partir da Constituição Federal de 1988, da Lei de Diretrizes e Bases da Educação Nacional $n^{\circ}$ 9394/96, das diretrizes do Conselho Nacional de Educação que são de 2000 e 2010. Esse caminho sinaliza fortes tendências: de um lado a oficialização da oferta da EJA como modalidade, ao mesmo tempo em que se distancia de suas características de luta política pela transformação da sociedade; de outro a juvenilização da modalidade, pois o fracasso da escola diurna empurra os jovens para as classes de EJA. Em Portugal, no essencial reflete-se acerca das condições histórico conjunturais, e influências supranacionais, que permitiram a emergência em 1996 de uma nova política e identidade na EJA em Portugal. Para tal analisam-se os marcos de várias políticas e programas dirigidos ao setor, e os contributos díspares das suas práticas discursivas, desde o advento da democracia em 1974, e da apresentação e implementação do Plano Nacional de Alfabetização e de Educação de Base de Adultos (PNAEBA), até ao recente Programa Qualifica (PQ).

\section{A identidade da EJA no Brasil: a agenda política pós-democracia e suas práticas discursivas}

O período pós abertura democrática no Brasil, após 21 anos de Ditadura Civil Militar, representou para a EJA um momento de fortalecimento da luta pela sua oficialização como 
política pública de Estado. Isto se explicita no arcabouço legal que é resultante das lutas dos movimentos sociais que defendiam a educação como um direito de todos e todas. Como resultante deste processo, a Constituição Federal de 1988 (BRASIL,1988), atualizada, afirma que,

Art. 205. A educação, direito de todos e dever do Estado e da família, será promovida e incentivada com a colaboração da sociedade, visando ao pleno desenvolvimento da pessoa, seu preparo para o exercício da cidadania e sua qualificação para o trabalho. [...] Art. 208. O dever do Estado com a educação será efetivado mediante a garantia de: [...] I. educação básica obrigatória e gratuita dos 4 (quatro) aos 17 (dezessete) anos de idade, assegurada inclusive sua oferta gratuita para todos os que a ela não tiveram acesso na idade própria; (Redação dada pela Emenda Constitucional $n^{\circ} 59$, de 2009) [...] II. progressiva universalização do ensino médio gratuito; (Redação dada pela Emenda Constitucional $n^{\circ}$ 14, de 1996) [...] III. atendimento educacional especializado aos portadores de deficiência, preferencialmente na rede regular de ensino; [...] IV. educação infantil, em creche e pré-escola, às crianças até 5 (cinco) anos de idade; (Redação dada pela Emenda Constitucional $n^{\circ} 53$, de 2006) [...] V. acesso aos níveis mais elevados do ensino, da pesquisa e da criação artística, segundo a capacidade de cada um;

VI. oferta de ensino noturno regular, adequado às condições do educando;

VII. atendimento ao educando, em todas as etapas da educação básica, por meio de programas suplementares de material didático-escolar, transporte, alimentação e assistência à saúde. (Redação dada pela Emenda Constitucional $n^{o}$ 59, de 2009) [...] $\S 1^{\circ} \mathrm{O}$ acesso ao ensino obrigatório e gratuito é direito público subjetivo. [...] $§ 2^{\circ} \mathrm{O}$ não oferecimento do ensino obrigatório pelo Poder Público, ou sua oferta irregular, importa responsabilidade da autoridade competente. $[\ldots] ; 3^{\circ}$ Compete ao Poder Público recensear os educandos no ensino fundamental, fazer-lhes a chamada e zelar, junto aos pais ou responsáveis, pela frequência à escola. (BRASIL, 1988, grifos nossos).

Os destaques em negrito nesses dois artigos da CF/1988 chamam a atenção para as prescrições que incluem a responsabilidade do Estado para com o atendimento da população jovem e adulta não escolarizada. As alterações que aparecem em destaque, a partir de 2009, com a aprovação da Emenda Constitucional no 59 (EC 59/2009), resultaram de mobilizações para a ampliação do direito à Educação Básica, que antes estava restrito ao Ensino Fundamental. Além da ampliação desse direito, o texto prevê o atendimento dos educandos pelos programas suplementares.

Os parágrafos que fecham o Artigo 208 são resultantes também das mobilizações dos setores que defendem a EJA, por entenderem que há condicionantes históricos que precisam ser enfrentados, se, de fato, queremos garantido o direito à educação. É preciso responsabilizar o poder público, caso ele não garanta a oferta, conforme determinam os parágrafos primeiro e segundo; cabe a esse mesmo poder público reconhecer que a demanda de alunos para a EJA precisa ser mobilizada; por isso, o parágrafo terceiro, tratando de recenseamento e zelo pela permanência dos alunos nos processos de escolarização. Tais mecanismos expressam a tentativa de efetivação do direito e da propalada democracia, defendida no contexto da educação brasileira por Teixeira (1936) e Lemme (2004). 
Tomando como referência essa questão das garantias de direito previstas na CF/1988, que se desdobraram em outras leis, portarias, decretos e resoluções, a EJA acompanha um movimento de ampliação da sua presença nesses aparatos, principalmente, a partir da Lei de Diretrizes e Bases da Educação Nacional - LDB (BRASIL,1996), quando passa a ser considerada modalidade da Educação Básica. Há diferentes posições entre os pesquisadores do campo a respeito desse cenário. Há quem considere que essa medida distanciou a EJA da sua matriz histórica da Educação Popular, como expressa Arroyo $(2005 ; 2007)$ em algumas de suas publicações; há quem perceba nesse processo uma conquista do ponto de vista da formalização da oferta escolar para jovens e adultos trabalhadores, como o faz Haddad (2007).

Em publicação recente, Costa e Machado (2017) analisam as principais iniciativas legais que envolveram o campo da EJA, destacando sua presença na CF/1988 (p. 62 a 63); na LDB/1996 (p. 65 a 69); no Parecer CNE/CEB no 11/2000, que orienta as diretrizes curriculares para EJA (p. 55 a 56, 58 a 61, 73 a 74); na Resolução CNE/CEB no 01/2000 (p. 70); nas minutas de pareceres para as Diretrizes Operacionais para EJA, que resultaram na aprovação da Resolução CNE/CEB no 03/2010 (p. 76 a 81); nos documentos finais das conferências nacionais de educação de 2010 e 2014, que influenciaram a Lei 13.005/2014 do Plano Nacional de Educação 2014-2024 (p. 82 a 91).

Para a reflexão deste artigo, não cabem reiterações acerca da presença da EJA no espaço da normatização das políticas educacionais. Há análises que as apresentam como potencial para o reconhecimento da escolarização de jovens e adultos trabalhadores, mas também há as que revelam o que há de contraditório entre o propagado e o realizado ${ }^{3}$. Ou, ainda, entre as inúmeras possibilidades de interpretação dessas leis em benefício de interesses outros que não coadunam com a garantia de uma educação de qualidade. $O$ que cabe reconhecer, mesmo guardando essa ressalva de que a prescrição legal não corresponde exatamente à efetivação do direito, é que, em torno dela ou de maneira conjunta, pode-se perceber uma ocupação do espaço da EJA na gestão pública, ou na sociedade política, e nas organizações sociais, que expressam a sociedade civil (GRAMSCI, 2007).

$\mathrm{O}$ destaque da atuação, no âmbito da sociedade política, evidencia-se com a presença da EJA nas estruturas administrativas nos âmbitos federal, estaduais e municipais. Observando os organogramas da administração pública federal, o Ministério da Educação (MEC) contava, em 1996, com uma coordenação de EJA dentro da Secretaria de Ensino Fundamental. A partir de 2004, com a criação da Secretaria de Educação Continuada, Alfabetização e Diversidade (Secad), é também criado o Departamento de EJA, que, naquele contexto, nasce com três coordenações: uma coordenação pedagógica, uma coordenação de alfabetização de coordenação de educação de jovens e adultos. Na estrutura do MEC, em 2019, o que se mantinha era a Secadi, pois a política de inclusão passou a fazer parte das atribuições dessa secretaria e a diretoria passou a denominar-se Diretoria de Políticas para a Juventude, Alfabetização e uma coordenação de Educação de Jovens e Adultos, composta das coordenações de Alfabetização, EJA e de Políticas para Juventude ${ }^{4}$.

A presença da EJA no âmbito das secretarias estaduais e municipais de educação tem, no período analisado, configurações muito diversas. Todavia, é notório que a indução das políticas federais, sobretudo com editais de financiamento e a aprovação de prescrições legais para a modalidade, influenciaram também para a constituição de espaços próprios para EJA. Denominadas diretorias, coordenações, gerências ou outras terminologias, o que se evidencia é que, à medida que a legislação nacional incorpora a EJA como modalidade de ensino e vincula à

\footnotetext{
${ }^{3}$ Beisiegel (2003); Paiva (2005); Di Pierro (2005); Machado (2009); Ireland (2009).

4 Informações a partir do site do MEC: <http://portal.mec.gov.br/secretaria-de-educacao-continuadaalfabetizacao-diversidade-e-inclusao/quem-e-quem>. Acessado em 19/10/2018.
} 
modalidade programas e ações no Plano Plurianual (PPA), os sistemas estaduais e municipais foram tencionados a incorporá-la nas estruturas políticas e pedagógicas das secretarias.

O exemplo mais evidente dessa relação indutora da União e da resposta dos demais entes federativos se percebe quando há o envolvimento de repasse de recursos definidos nos PPAs. Os valores mais próximos das aplicações em EJA, descentralizados pelo governo federal entre os anos de 2006 a 2014, estão publicados num relatório sobre as ações e programas implementados pelo Brasil, que avaliou o compromisso do governo federal, seis anos após sediar a VI Conferência Internacional de Educação de Adultos (VI Confintea) ${ }^{5}$ em 2009 (BRASIL, 2016, p. 52-56) ${ }^{6}$.

Como a matrícula na EJA é de responsabilidade, principalmente, dos governos estaduais e municipais, os recursos descritos no referido relatório só podem ser considerados como complementares para a ampliação e manutenção da modalidade. Ainda assim, dimensionam esse movimento que diversificou os aportes financeiros, incluindo recursos para alimentação, transporte, material pedagógico, livro didático, formação e capacitação de profissionais da educação, aquisição de biblioteca de EJA, bolsas para alfabetizadores e coordenadores de turmas do Programa Brasil Alfabetizado, dentre outras ações. A dinâmica definida pelo departamento de EJA do MEC foi, naquele contexto, a descentralização dos recursos para que estados e municípios executassem e prestassem contas à União.

Um último aspeto ainda vinculado à questão do financiamento da EJA, muito discutido no período entre 1988 a 2018, é a presença ou não dessa modalidade na lógica contábil do financiamento da educação, a partir da implantação das políticas de fundos, ou seja, em 1996, com o Fundo de Manutenção e Desenvolvimento do Ensino Fundamental e Valorização do Magistério (Fundef) ${ }^{7}$ e, em 2007, a ausência total de consideração das matrículas da EJA no Fundef será substituída por uma presença marginal no Fundeb ${ }^{8}$.

Todas essas iniciativas legais e administrativas de atuação da sociedade política na pauta da EJA contaram, para sua efetivação como direito, com uma pressão e atuação diversificada de vários setores da sociedade civil. Historicamente, a educação de adultos, chamada de educação popular nos idos das décadas de 1950 e 1960, foi um campo de disputa entre interesses, inclusive antagônicos. Setores das igrejas, dos empresários, dos sindicatos, das organizações não-governamentais, dos movimentos sociais do campo e da cidade estão presentes nas propostas e iniciativas de escolarização de jovens e adultos. Essa ainda é a realidade que revela concepções de mundo em disputa. As pesquisas e publicações que hoje estão disponíveis na Web acerca da EJA podem ser uma das formas para acessar essas diferentes concepções.

\section{A identidade da EJA em Portugal: a agenda política pós-democracia e suas práticas discursivas}

Em Portugal, o panorama de 48 anos de regime ditatorial cessou com a operação 'Fim de Regime', executada pelo movimento militar, iniciando-se, a partir de 1974, uma fase curta,

\footnotetext{
5 A publicação organizada por Ireland \& Spezia (2012) apresenta uma importante retrospectiva dessas conferências coordenadas pela Unesco, desde a primeira em 1949 à última em 2009. Além de situar a contribuição dessas conferências para a política de educação de adultos entre os países-membros da ONU, a publicação traz em anexo todas as declarações resultantes das seis conferências (várias delas traduzidas por primeira vez para o português).

${ }^{6} \mathrm{O}$ referido relatório trata-se de um registro histórico de avaliação da política de EJA no Brasil, elaborado por uma comissão intersetorial e com representação da sociedade política e civil, contendo além de diagnóstico da realidade, indicações importantes para a revisão dessa política. A produção na íntegra pode ser acessada no endereço: 〈http://confinteabrasilmais6.mec.gov.br>. Acessado em 19/10/2018.

${ }^{7}$ Lei no 9424 de 24 de dezembro de 1996. Disponível em: <http://www2.camara.leg.br/legin/fed/ lei/1996/lei9424-24-dezembro-1996-365371-publicacaooriginal-1-pl.html>. Acessado em 19/10/2018.

${ }^{8}$ Lei n ${ }^{\circ} 11.494$ de 20 de junho de 2007. Disponível em: <http://www.planalto.gov.br/ccivil_03/_Ato20072010/2007/Lei/L11494.htm>. Acessado em 01/02/2019.
} 
mas intensa, de rupturas profundas na sociedade portuguesa, conhecida como o período revolucionário, que termina em 1976, com o novo regime constitucional.

Neste interregno viveu-se uma crise política que expressou contradições entre diferentes frações ideológicas da elite dirigente. Em confronto, estiveram dois projetos ideológicoestratégicos principais: de um lado, um modelo democrático socializante de base parlamentar, inspirado nas democracias ocidentais europeias; e do outro, um modelo revolucionáriosocialista de base populista, inspirado na realidade coletivista da Europa de leste e da Rússia. Ora, o impacto desta confrontação na futura estruturação da formação social portuguesa configuraria uma das suas principais especificidades, a que Sousa Santos (1990) designou de Estado dual, e que consiste na coexistência, desde logo complexa e contraditória, de uma vasta burocracia tradicional do Estado com um leque de novas instituições. No campo da educação de adultos o conceito de Estado dual, explica cabalmente, no nosso entender, a atuação da Direção Geral de Educação Permanente (DGEP), um dos organismos oficiais que teve maior relevância na história portuguesa das estruturas administrativas do setor, sobretudo pela busca e operacionalização de um novo tipo de relações entre a administração do Estado e as iniciativas sociais, destacando-se neste particular a iniciativa de apoiar com meios e consolidar estatutariamente, através da figura da 'associação de educação popular', muitas das experiências associativas avulsas realizadas em consequência do ímpeto revolucionário vivido na época.

Durante o período revolucionário, dar-se-ia uma alteração profunda, embora efêmera, no equilíbrio de forças operantes na regulação social, de tal forma que "o poder desloca-se do Estado para a sociedade civil e a ação daquele é, numa primeira fase, posta em causa e substituída pela ação popular" (LIMA et al., 1988, p. 80), o que significaria a emergência de fortes contradições, e alguns bloqueios, no contexto sociopolítico de desenvolvimento da educação de adultos. Assim, no domínio estatal da regulação do setor podem-se distinguir, duas fases na atuação da DGEP. A primeira fase, entre abril de 1974 e novembro de 1975, em que se destaca a constituição de um grupo de trabalho encarregue de elaborar, em Maio de 1975, um Plano Nacional de Alfabetização (PNA). Este plano que no panorama nacional da época se sucede quer às Campanhas de Dinamização Cultural (CDC), conduzidas pelo Movimento das Forças Armadas (MFA), quer às Ações de Alfabetização (AA), tinha como principal objetivo reduzir, em apenas três anos, a taxa de analfabetismo de $23 \%$ para $3 \%$, promovendo atividades que se deveriam desenrolar do centro para a periferia e da cidade para o campo, numa lógica de atuação geral que Stoer (1986) denominou como a corrente de alfabetização, e Barbosa (2004) designou de tendência sistêmico-institucional, e que representou um projeto de produção acelerada de diplomados, (LIMA, 2005). Ora, após o verão quente de 1975, e do contragolpe de 25 de Novembro, tomou posse, em Dezembro, Alberto Melo como novo Diretor-geral na DGEP, que iniciou uma reorganização e reorientação da política de educação de adultos para promover um tipo novo de intervenção estatal, orientado para "dar respostas às solicitações vindas dos grupos de base (...) e envolver prioritariamente as populações a que tradicionalmente foi vedado o acesso aos meios de expressão e de aquisição de conhecimentos indispensáveis à participação plena na vida social" (DGEP, 1978, p. 4). A nova agenda política adotou os princípios do paradigma da educação permanente, nos termos do Relatório de Faure et al. (1972) e das Recomendações da UNESCO, tendo sido a sua atuação política particularmente legitimada pela nova Constituição da República, de $1976^{9}$ que, no referente à educação e ensino afirma,

\footnotetext{
${ }^{9}$ A lei fundamental aprovada em 1976, tem sido apontada como um produto do período revolucionário, pelo que continha de compromisso conflitual entre os pressupostos oriundos dos diferentes quadrantes políticos e doutrinários, basicamente entre justiça social e liberdade de mercado, mas, principalmente, por apontar como supremo objectivo, a par da consagração dos direitos fundamentais e da defesa do pluripartidarismo, a transição para o socialismo, conferindo destaque ao papel dirigente do Estado, à irreversibilidade das nacionalizações e impondo restrições à propriedade e iniciativa privadas, no fundo, tratando de salvaguardar a construção de uma
} 
ARTIGO 73..$^{\circ}$

(Educação e cultura)

2. O Estado promoverá a democratização da educação e as condições para que a educação, realizada através da escola e de outros meios formativos, contribua para o desenvolvimento da personalidade e para o progresso da sociedade democrática e socialista.

ARTIGO 74. ${ }^{\circ}$

(Ensino)

1. O Estado reconhece e garante a todos os cidadãos o direito ao ensino e à igualdade de oportunidades na formação escolar.

2. O Estado deve modificar o ensino de modo a superar a sua função conservadora da divisão social do trabalho.

3. Na realização da política de ensino incumbe ao Estado:

a) Assegurar o ensino básico universal, obrigatório e gratuito;

b) Criar um sistema público de educação pré--escolar;

c) Garantir a educação permanente e eliminar o analfabetismo;

d) Garantir a todos os cidadãos, segundo as suas capacidades, o acesso aos graus mais elevados do ensino, da investigação científica e da criação artística;

e) Estabelecer progressivamente a gratuitidade de todos os graus de ensino;

f) Estabelecer a ligação do ensino com as actividades produtivas e sociais;

g) Estimular a formação de quadros científicos e técnicos originários das classes trabalhadoras.

ARTIGO 75. ${ }^{\circ}$

(Ensino público e particular)

1. O Estado criará uma rede de estabelecimentos oficiais de ensino que cubra as necessidades de toda a população.

2. O Estado fiscaliza o ensino particular supletivo do ensino público. ARTIGO $76 .^{\circ}$

(Acesso à Universidade)

$\mathrm{O}$ acesso à Universidade deve ter em conta as necessidades do país em quadros qualificados e estimular e favorecer a entrada dos trabalhadores e dos filhos das classes trabalhadoras.

Neste âmbito, a DGEP protagonizou um relevante esforço legislativo ${ }^{10}$ no sentido de desconcentrar projetos e apoiar as atividades de base em regiões mais desfavorecidas, constituindo aquilo a que Stoer (1986) chamou como a corrente do poder popular, e a que Barbosa (2004) designou como tendência humanista-comunitária.

Nesta nova fase na atuação da DGEP privilegiou-se uma abordagem que assentava na auscultação das solicitações existentes que possibilitou, de forma totalmente inovadora na administração pública, que o movimento associativo popular entrasse nos aparelhos do

sociedade sem classes e sem exploração do Homem pelo Homem (Moreira, 1992; Magalhães, 1996; 1999). Daniel Bessa, sublinhará a este propósito que, "para além de tudo o que possa discutir-se acerca do espírito da Constituição de 1976, parece indiscutível que será difícil encontrar um enunciado expresso de direitos materiais do cidadão e das obrigações correlativas do Estado mais extenso do que nela se consagra" (Bessa, 1985, p. 336-337).

${ }^{10}$ Destacando-se em especial os normativos: o Decreto-Lei no 384/76 de 20 de Maio; a Portaria $n^{\circ}$ 419/76 de 19 de Julho; e os Despachos no 29/76 e nº 53/76. 
Estado, se institucionalizasse e começasse a fazer parte das suas próprias estruturas. Porém, a partir de 1976, com o processo de normalização política pós-revolucionária, verificar-se-ia uma interrupção abrupta da ação inovadora conduzida pela DGEP, verificando-se que "a maioria das atividades acabam, uma a uma, por ser suspensas (...) dando uma sensação de vazio e uma imagem de semiparalisação, até que em finais de Junho de 1978 toma posse um novo Diretor-geral" (DGEP, 1978, p. 9-10). A partir de então, se desencadearam os trabalhos preparatórios do Plano Nacional de Alfabetização e de Educação de Base de Adultos (PNAEBA), que veio a constituir "um notável documento e quadro de referência de todas as iniciativas, no domínio da educação de adultos, conduzidas ou apoiadas pelo Estado, a partir do último trimestre de 1979" (DGEE, 1991, p. 58). Por outras palavras, na esfera da produção de políticas públicas, trata-se do mais amplo e ambicioso Plano, inscrito num entendimento alargado da educação de adultos, que seria elaborado até hoje, pelo que se transformaria, talvez precisamente por não ser um plano diretivo mas um quadro de orientações, num marco incontornável (sucessivamente convocado) para o projeto (sucessivamente adiado) de construir um sistema público e holístico de educação de adultos em Portugal.

Rapidamente se verificaria, porém, em contexto de normalização política, que “à elaboração do Plano não corresponderam as medidas de política previstas e a inércia administrativa ou resistências políticas (provavelmente uma e outra coisa) travaram, desde o início, ao nível do poder de Estado, a sua execução" (SANTOS SILVA, 1990, p. 28). Significativamente, pois, não só não se realizaria a segunda fase de execução ${ }^{11}$ concebida no PNAEBA, abandonado em 1985, como o cumprimento da primeira fase ficou abaixo dos objetivos traçados.

Com a entrada de Portugal na Comunidade Econômica Europeia (CEE) em 1986, iniciou-se a reforma educativa portuguesa que assentou na Comissão de Reforma do Sistema Educativo (CRSE) e na Lei no 46/86, de 14 de Outubro - Lei de Bases do Sistema Educativo (LBSE). Ora, no articulado da LBSE é feita uma abordagem dispersa ao setor, em que a educação de adultos apenas é conceptualizada numa ótica subalterna de modalidade especial de educação (art. ${ }^{\circ} 16$ ), onde se contemplam o ensino recorrente de adultos (ERA), a formação profissional (FP) e o ensino a distância (ED); e numa ótica minimalista de educação extraescolar (EEE) (art. ${ }^{\circ} 23$ ), onde é objeto de generalizações dispersas, que não fazem jus ao seu carácter tradicionalmente abrangente e multifacetado. Com base nesta lei a rede pública seria fixada refletindo o reducionismo conceptual que a enclausurou no ensino recorrente, sobretudo um sistema de escolarização compensatória. Chega-se, pois, a meados da década de noventa com um cenário nacional em que o tripé de sustentação das políticas públicas de educação de adultos consistia: primeiro, no claro abandono financeiro das modalidades de tipo não escolar e matriz não vocacionalista ou profissionalizante; segundo, na forte indução, pelos organismos públicos e os financiamentos europeus, de novas intervenções sociais que raramente tiveram, como principal objetivo, ações de educação de adultos amplamente entendida; e terceiro, pela progressiva deslegitimação e pulverização do setor em termos do seu próprio enquadramento institucional ${ }^{12}$. Constatando-se, neste último aspeto, que as

\footnotetext{
${ }^{11}$ O Plano-quadro foi concebido para o horizonte temporal de uma década, estando perspetivadas duas fases de execução com a duração de cinco anos cada.

12 As estruturas administrativas para a Educação de Adultos desde 1974 até meados da década de noventa, compreenderam significativas mudanças desde a pioneira Direção-Geral de Educação Permanente (DGEP). Com efeito, depois da LBSE, o setor sofre três mudanças significativas ao nível da sua administração central, tendo a Direção-Geral da Educação de Adultos (DGEA), que sucedeu à DGEP, sido extinta em 1987 (Decreto-Lei n. ${ }^{\circ}$ 3/87, de 3 de Janeiro) para dar lugar à Direção-Geral de Apoio e Extensão Educativa (DGAEE), que ao contrário da primeira, já não se constitui como estrutura específica, única e autônoma para a educação de adultos, e que em apenas um ano se veria de novo reconfigurada (Decreto-Lei n. ${ }^{\circ}$ 362/89, de 19 de Outubro) como Direção-Geral de Extensão Educativa (DGEE), que em 1993 seria, por seu turno, também extinta, em moldes que acentuariam o
} 
sucessivas leis orgânicas do Ministério da Educação deram "um sinal claro da crescente diluição e consequente perda de autonomia e especificidade do subsistema de educação de adultos" (SANTOS SILVA; ROTHES, 1998, p. 31).

Com o novo protagonismo da União Europeia (UE) na área da educação, adquirido após o Tratado de Maastricht (1992), temos defendido que o setor passou a ser objeto de uma governação pluriescalar, que em Portugal se verificou, a partir 1996, através da execução de uma agenda globalmente estruturada, implementada em múltiplos níveis com crescente complexificação (BARROS, 2013; BARROS; BELANDO-MONTORO, 2013). No âmbito deste processo ocorreram medidas que conduziriam a uma reconsideração política do setor, sendo de destacar o lançamento do Programa de Ação S@bert: Programa para o Desenvolvimento e Expansão da Educação e Formação de Adultos, 1999-2006, que entre outros objetivos, visou colocar os alicerces de uma nova oferta, e de uma nova conceptualização do campo, que deixou oficialmente de ser de educação de adultos (EA) para passar a ser de educação e formação de adultos (EFA), originando-se quer uma reconversão da identidade histórica desta área quer a renovação das suas práticas discursivas balizadas, desde então, pela nova política de EFA a nível nacional, e pelo paradigma da aprendizagem ao longo da vida a nível europeu (BARROS, 2011a; 2012).

Com efeito, surgiram atividades que se destinaram, no essencial, a ir ao encontro da frágil situação educacional da população ativa mediante a "criação de soluções flexíveis que articulem a educação e a formação, através de percursos organizados, a partir de processos de reconhecimento e validação de saberes adquiridos e de sistemas modulares de formação" (ANEFA, 2001, p. 29). A par do Ensino Recorrente de Adultos (ERA), básico e secundário, e da Educação Extraescolar (EEE), a estruturação da nova oferta pública de EFA compreendeu, a partir deste período, as seguintes modalidades: uma oferta de Cursos de Educação e Formação de Adultos (Cursos EFA); uma oferta de Ações S@ber+; e uma oferta de Reconhecimento, Validação e Certificação de Competências (RVCC). Registando-se, assim, um real alargamento da rede nacional afeta ao setor, e portanto, antes de mais, uma expansão da diversificação da oferta (BARROS, 2016a).

Ora, o impacto da regulação supranacional da aprendizagem ao longo da vida, tendencialmente baseada na avaliação de resultados (economicamente) significativos, fez-se notar na EFA portuguesa mediante a emergência de novos instrumentos de governabilidade, tanto de planeamento como de orientação e de concertação social, onde proliferam discursos consonantes com o novo gerencialismo que vem enformando, desde então, a elaboração de políticas públicas (BARROS, 2019), apontando para duas vertentes principais, designadamente: para a ideia explícita de moralizar o sistema educacional, que para o setor assentou sobretudo na promoção da igualdade de oportunidades, fomentada, segundo amplamente se publicitou, pela criação de novas oportunidades; e para a ideia implícita de promover o controlo social, que para o setor assentou na ideia da responsabilização individual pela empregabilidade através de mais educação e formação, de preferência ao longo de toda a vida, e em todos os lugares da vida. Com base neste quadro, a Iniciativa Novas Oportunidades - 2006-2012 (INO) surge como um instrumento político de síntese, representando um elemento paradigmático na governação educacional pluriescalar para o setor da nova EFA.

processo de dispersão e despromoção entretanto iniciado, na medida em que o setor passa, em termos do seu estatuto administrativo, a representar um apêndice do sistema nacional de educação, a que já só corresponde organicamente (Decreto-Lei n. ${ }^{\circ}$ 133/93, de 26 de Abril) um Núcleo do Ensino Recorrente e Educação ExtraEscolar, estando a sua coordenação subdividida entre o Departamento do Ensino Básico (DEB) e o Departamento do Ensino Secundário (DES). Neste panorama, sobressai ainda a integração do ensino recorrente de adultos (ERA) nas Coordenações de Área Educativa (CAE), criadas no âmbito das Direções Regionais de Educação (DRE) resultantes de uma reorganização do Ministério da Educação (Decreto-Lei n..$^{\circ}$ 361/89, de 18 de Outubro). 
Assim sendo, a estratégia da INO retomou e aprofundou as inovações de maior execução e financiamento introduzidas pelo Programa $s @ b e r+$, e assentou em dois pilares fundamentais, por um lado, na ideia de dar 'oportunidades novas' aos jovens através do incremento de cursos técnicos e profissionais e, por outro lado, na ideia de dar uma 'nova oportunidade' aos adultos ativos através do aumento dos Cursos EFA e do Processo de RVCC. Para ambos os eixos, foram estabelecidas metas concretas a atingir anualmente em cada um dos Centros Novas Oportunidades (CNO) da rede pública nacional. Embora com importantes ambivalências, a INO traduziu-se, de fato, numa democratização do acesso à EFA, com a inscrição expressiva de mais de $10 \%$ da população portuguesa, como alguns estudos de avaliação demostraram (CARNEIRO, 2011; LIZ, MACHADO, BURNAY, 2009), permitindo que, entre 2000 e 2010, 386463 indivíduos fossem certificados, para o caso do RVCC escolar, e 68255 para os Cursos EFA (ANQ, 2011). Ora, não estando em causa o potencial do reconhecimento dos adquiridos experienciais da população adulta (BARROS, 2011b; 2014a; 2016b; BARROS; FERREIRA, 2018), surgiram diversos estudos oriundos da academia que recomendavam quebrar com a lógica paliativa com que as ofertas de EFA estavam a ser concebidas (CAVACO; LAFONT; PARIAT, 2014; LIMA, 2014; MARQUES, 2014) no âmbito do novo paradigma das políticas para as estatísticas, traduzido no setor sobretudo pela importância do International Adult Literacy Survey - IALS, e do Programme for the International Assessment of Adult Competencies - PIAAC. Observa-se, pois, que a principal tendência portuguesa identificada nas práticas discursivas de EFA é a de se apresentarem eminentemente híbridas, espelhando as tensões intrínsecas à sua governação e desenvolvimento, cuja essência humanista, promovida pela UNESCO, não se compatibiliza com a formação instrumental de recursos humanos, incentivada pela UE.

Com este enquadramento pluriescalar, a agenda nacional dos programas políticos destinados à governabilidade hodierna do setor apresenta importantes contradições (BARROS, 2014b; 2018). Porém, a intermitência dos mandatos e, portanto, a típica vulnerabilidade deste setor $^{13}$ ficou radicalmente patente sobretudo no período compreendido entre 2012-2015, no qual também aqui se impôs severas políticas de austeridade conducentes diretamente à extinção da rede de CNO. Surgem, então, novos centros designados de Centros para a Qualificação e o Ensino Profissional (CQEP), porém em muito menor número que os anteriores e, como seria de esperar face à adoção de políticas neoliberais, sem qualquer financiamento. Foi feita uma reconversão do setor, que se escolariza com a desvalorização do habitual portfólio biográfico e a introdução nas práticas de RVCC de uma prova de inspiração escolar. Ora, esta caraterística, nova em Portugal no âmbito do processo de reconhecimento de adquiridos experienciais, apareceu justificada no discurso público como uma pretensão de atribuir mais rigor ao processo, que sofreu algum descrédito na fase de expansionismo acelerado da rede de CNO. Porém, novas e problemáticas contradições foram incorporadas nos dispositivos. Com efeito, durante este período recente, prevaleceu uma ação política nacional impositiva, legitimada por uma aliança supranacional, inscrita numa 'economia

\footnotetext{
${ }^{13}$ Este aspeto está historicamente traduzido quer (1) nas alterações das estruturas administrativas, que desde meados da década de noventa, até hoje, compreendeu: a ANEFA - Agência Nacional de Educação e Formação de Adultos (Decreto-Lei n. ${ }^{\circ}$ 387/99, de 28/9), a DGFV - Direção Geral de Formação Vocacional (Despacho 21 974/2002 de 25 de Setembro e Decreto-lei 208/2002 de 17 de Outubro), a ANQ - Agência Nacional para a Qualificação (Decreto-lei n. ${ }^{\circ}$ 213/2006, de 27 de Outubro) e a ANQEP - Agência Nacional para a Qualificação e o Ensino Profissional (Decreto-Lei n. ${ }^{\circ}$ 36/2012, de15 de Fevereiro); quer (2) nas alterações dos espaços próprios para as práticas da Educação de Adultos portuguesa, que desde 2000 até hoje, transitariam de: uma Rede Nacional de Centros de Reconhecimento, Validação e Certificação de Competências (CRVCC), para uma Rede Nacional de Centros Novas Oportunidades (CNO), para uma Rede Nacional de Centros para a Qualificação e Ensino Profissional (CQEP), para, a mais recente, Rede Nacional de Centros Qualifica (CQ).
} 
política do retrocesso' (REIS, 2014) através da qual a EFA em Portugal praticamente desapareceu da agenda política.

Com as alterações governativas de finais de 2015, foram criados os atuais Centros Qualifica (CQ). E, em contraciclo com as medidas anteriores, observa-se agora uma retoma do setor na agenda política através da criação do Programa Qualifica. Ora, entre outros aspetos o Governo em funções herdou a crise de legitimidade das severas medidas neoliberais de ajustamento da sociedade e do Estado quer às demandas supranacionais quer aos agentes financeiros nacionais, que têm vindo a pressionar visivelmente a macroestrutura no sentido da privatização dos lucros e da socialização dos prejuízos. Não sendo expectável que a ação governativa fosse suspender a política de austeridade, verificou-se, no entanto, um reconhecimento sutil no novo discurso público de que há alternativas contrárias ao empobrecimento dos Estados e das populações e que se pode dar um uso menos ortodoxo à margem (estreita) de manobra que uma certa soberania nacional ainda permite.

Portanto, em Portugal, as várias escalas inter-relacionadas de governação da nova EFA (supranacional, nacional e subnacional), que no nosso entender, ganharam uma acentuada complexidade na última década, espelham uma identidade do setor que apresenta significativas ambivalências.

\section{A realidade da EJA se difere e se aproxima entre Brasil e Portugal}

A compreensão das práticas discursivas inerentes à agenda política voltada para EJA, destacando a ação do Estado a partir do advento da Democracia no Brasil e em Portugal, nos possibilita perceber que, embora os processos de redemocratização dos dois países tenham se configurado em contextos diferenciados, há aproximações entre o desenho e a implementação das políticas educacionais que foram colocadas em prática, em diferentes governos, por vezes configurando-se em políticas de Estado.

Da diferenciação entre os contextos de redemocratização, cabe ressaltar que Portugal vivenciou, no seu cenário político, um momento considerado revolucionário, o que não ocorreu no Brasil. Este aspeto é relevante, se considerarmos que foi exatamente neste contexto revolucionário, em Portugal, que a relação do Estado com a sociedade civil se intensifica, sendo espaço propício para a incorporação das políticas sociais defendidas no âmbito da sociedade civil. É o momento em que a educação de adultos passa a ser reconhecida na sua especificidade e como prioridade para a reconstrução do país.

No Brasil, a redemocratização após os vinte e um anos de Ditadura Militar, foi uma negociação entre os interesses das elites nacionais e internacionais. Sem sombra de dúvidas, os que resistiam às imposições do Regime dentro do país e fora, como exilados, tiveram papel importantíssimo para a reconstrução democrática. Todavia, essa reconstrução não teve a marca de movimento revolucionário, nem representou, imediatamente, mudança significativa na pauta da educação de adultos no país. A mudança observada nas políticas para a educação de adultos vai se explicitar já em meados da primeira década do Século XX, com as políticas implementas nos governos liderados pelo Partido dos Trabalhadores.

Esta ressalva sobre a natureza dos processos de redemocratização dos dois países, não nos impede de destacar, mantidas as devidas especificidades geográficas, culturais, mas sobretudo, econômicas e políticas entre Brasil e Portugal, as aproximações entre as proposições normativas que passaram a orientar a política de educação de adultos. $\mathrm{O}$ foco da legislação nos dois países passa a tratar educação como direito de todos e obrigação do Estado, sendo de incontornável importância o teor e o espírito das Primeiras Constituições do novo período democrático.

A visível ocupação de espaço na agenda educacional pelo campo da educação de adultos se expressa na legislação e nos programas criados para dar conta da tarefa, que se iniciava na 
alfabetização, passava pela formação profissional e educação superior, constituindo-se numa pauta de educação e formação permanente. No caso brasileiro, a agenda da educação de adultos é tão implicada na realidade de não escolarização da população como um todo, que passa a abarcar a juventude em suas estratégias de escolarização, alterando sua identidade anterior e por isso as diretrizes políticas passam a tratá-la como Educação de Jovens e Adultos.

Para além do arcabouço normativo e diretivo das ações em educação para jovens e adultos, as estruturas oficiais em nível federal e locais, tiveram que abrir espaço para a execução dos planos, projetos e programas criados. A realidade dos dois países revela que a pauta exigiu a criação, onde não existia, ou a adequação de estruturas físicas e administrativas para dar conta do desafio de escolarização e formação permanente de jovens e adultos. Isto sem desconsiderar a mobilização e, necessária, preparação de profissionais que pudessem responder aos desafios da mediação do conhecimento com estes sujeitos. Todavia, os esforços observados nesta direção não foram isentos da influência e pressão por um certo modus operandi que insiste em manter a referência a uma escola para crianças e adolescentes e uma lógica de segunda oportunidade para adultos. As experiências que buscaram entender as demandas da sociedade civil, sobretudo as que pensavam numa perspectiva de educação como espaço de resgate e emancipação dos sujeitos, nem sempre foram consideradas, quando das decisões político-administrativas, dos investimentos financeiros e de infraestrutura para a execução dos programas.

Observando as diferentes estratégias implementadas nos dois países e considerando os limites para a consolidação de políticas de Estado, que ultrapassassem os contextos dos governos, a cada pleito eleitoral, pode-se perceber que a agenda da educação de jovens e adultos foi sendo orientada para atender mais a interesses políticos do que garantir o direito a educação, entendido como o acesso irrestrito e usufruto pleno e bem-sucedido aos conhecimentos produzidos e sistematizados pela Humanidade, convocados no patrimônio mobilizado pela educação formal e não formal de cariz público.

Este aspeto nos remete às concepções de educação e mundo reveladas por estas iniciativas educacionais, quando as alterações nas propostas ocorrem, por exemplo, por pressões internacionais, como na experiência de Portugal, para atender a interesses de mercado. No caso brasileiro, mesmo reconhecendo as ações importantes realizadas sobretudo entre os anos de 2004 a 2014, a descontinuidade tem sido uma das marcas mais relevantes na condução de programas, projetos e ações para a EJA, dificultando sua consolidação como política pública. Naquilo que não se evidencia de descontínuo, identifica-se uma precarização do processo de aprendizagem, pelas práticas pedagógicas aligeiradas e compensatórias que ainda são muito presentes nas iniciativas de EJA no país.

As distâncias que são encontradas entre as práticas discursivas, no campo da formulação das políticas, e a garantia do acesso ao conhecimento, e não apenas à certificação, aproximam em grande medida a experiência de educação de jovens e adultos de Brasil e Portugal. Não desconsiderando o peso que tem sobre isto outros aspetos da prática educativa, ressaltamos que as práticas discursivas inerentes à agenda política dos dois países, ressalvados momentos isolados, tem se configurado em estratégias de manutenção de sujeitos em condição de subalternidade aos interesses de uma lógica capitalista desigual e combinada.

\section{Considerações finais}

A história da Educação de Jovens e Adultos se consolidou internacionalmente como um campo de inter-relação do conjunto das suas três dimensões constituintes principais em necessária, contraditória e processual relação: o campo de práticas educativas; o campo de práticas de investigação; e o campo de práticas discursivas. Neste artigo quisemos enfatizar aspetos das práticas discursivas inerentes à agenda política, e portanto, à ação do Estado, a partir do advento da democracia quer no Brasil quer em Portugal. Verificamos que em ambos 
os contextos a EJA revela facetas múltiplas, que justificam a intensificação da sua presença nas agendas investigativas das Universidades.

As reflexões aqui apresentadas indicam que, apesar do patrimônio internacional da educação de adultos revelar importantes marcos na história geral da educação, construídos à luz de um paradigma sócio crítico e de um modelo de sociedade pautado pela busca de uma maior justiça social e usufruto de direitos, essas ações sofrem intervenções de decisões governamentais que as vão modificando, num processo conflitivo de avanços e recuos civilizacionais. As aproximações e os distanciamentos que evidenciamos neste texto entre a EJA brasileira e a portuguesa iluminam tão só alguns aspetos desta historiografia, que precisa ser mais desenvolvida, explicitada e problematizada.

\section{Referências}

ANEFA. Plano de Atividades 2001. Lisboa: ANEFA, 2001.

ANQ. Linhas orientadoras para o futuro da iniciativa novas oportunidades. Lisboa: Agência Nacional para a Qualificação, 2011.

ARROYO, Miguel. Balanço da EJA: o que mudou nos modos de vida dos jovens-adultos populares? REVEJ@ - Revista de Educação de Jovens e Adultos, v. 1, n. 0, p. 1-108, ago. 2007.

ARROYO, Miguel. Educação de Jovens e Adultos: um campo de direitos e de responsabilidade pública. In: SOARES, Leôncio; GIOVANETTI, Maria A.; GOMES, Nilma L. Diálogos na educação de jovens e adultos. Belo Horizonte/MG, Autêntica, 2005, p. 19- 50.

BARBOSA, Fátima. A Educação de Adultos - Uma Visão Crítica. Porto: Estratégias Criativas, 2004.

BARROS, Rosanna. The Role of Transnational Bodies in Lifelong Learning and the Politics of Measurement - The global promise and national pitfalls of outcomes-based assessment into Recognition of Prior Learning System in Portugal. In: FERGAL FINNEGAN; Bernie GRUMMELL (Eds). Power and Possibility: Adult Education in a Diverse and Complex World. Rotterdam: Sense Publishers, 2019. https://doi.org/10.1163/9789004413320_005

BARROS, Rosanna. A 'Nova Política de Educação e Formação de Adultos' em Portugal: Crítica à Governação Neoliberal do Setor em Contexto de Europeização. Ensaio - Avaliação $e$ Políticas Públicas em Educação, vol. 26, $\mathrm{n}^{\mathrm{o}} . \quad 100, \quad 573-594,2018$. https://doi.org/10.1590/s0104-40362018002601050

BARROS, Rosanna. Diversificação, Massificação e Esvaziamento da Oferta de Educação e Formação de Adultos (EFA) em Portugal: Algumas Reflexões e Inquietações, Revista Portuguesa de Pedagogia, 50 - 1, 13-36, 2016a. https://doi.org/10.14195/1647-8614_50-1_1

BARROS, Rosanna. The Portuguese case of RPL new practices and new adult educators: Some tensions and ambivalences in the framework of new public policies. In P. Andersson, A. FEJES; F. SANDBERG (Eds), Researching recognition of prior learning around the globe. London: Routledge, 2016b. https://doi.org/10.1080/02601370.2013.778071 
BARROS, Rosanna. A Conceção e Implementação da Nova Política de Educação e Formação de Adultos em Portugal: sinopse histórica de uma viragem na agenda política nacional (19961999). In Natália ALVES, Sónia Maria RUMMERT e Marcelo MARQUES (Org.). Educação e Formação de Jovens e Adultos em Portugal e no Brasil: Políticas, Práticas e Atores (pp. 13-29). Lisboa: Instituto de Educação da Universidade de Lisboa, 2014a.

BARROS, Rosanna. The Portuguese recognition of prior learning (RPL) policy agenda: Examining a volatile panacea by means of ethno-phenomenological interpretations. Encyclopaideia, Journal of Phenomenology and Education, XVIII(40), 53-68, 2014b.

BARROS, Rosanna. As políticas educativas para o sector da educação de adultos em Portugal: As novas instituições e processos educativos emergentes entre 1996-2006. Lisboa: Chiado Editora, 2013. https://doi.org/10.12957/e-mosaicos.2014.12835

BARROS, Rosanna. From Lifelong Education to Lifelong Learning: Discussion of some effects of today's neoliberal policies. RELA - European Journal for Research on the Education and Learning of Adults, Vol. 3, No.2, 2012, 119-134, 2012. https://doi.org/10.3384/rela.2000-7426.rela0071

BARROS, Rosanna. Genealogia dos Conceitos em Educação de Adultos: Da Educação Permanente à Aprendizagem ao Longo da Vida - Um estudo sobre os fundamentos políticopedagógicos da prática educacional. Lisboa: Chiado Editora, 2011a. https://doi.org/10.21814/rpe.2996

BARROS, Rosanna. A Criação do Reconhecimento de Adquiridos Experienciais (RVCC) em Portugal - Uma Etnografia Crítica em Educação de Adultos. Lisboa: Chiado Editora, 2011b.

BARROS, Rosanna; FERREIRA, Júlia. A Criação e Evolução do Reconhecimento de Adquiridos Experienciais em Portugal. In Carmen CAVACO (Org.). Reconhecimento, validação $e$ certificação de adquiridos experienciais em Portugal, França, Bélgica e Itália / Reconnaissance, validation et certification des acquis de l'expérience au Portugal, France, Belgique et Italie (pp.43-74). Lisboa: Instituto de Educação da Universidade de Lisboa (E-BOOK), 2018.

BARROS, Rosanna; BELANDO-MONTORO, Maria. Europeização das Políticas de Educação de Adultos: Reflexões Teóricas a partir dos Casos de Espanha e Portugal, Education Policy Analysis Archives, Vol. 21, No. 71, 1-28, 2013. https://doi.org/10.14507/epaa.v21n71.2013

BEISIEGEL, Celso de Rui. Alfabetização de jovens e adultos: desafios do século 21. In: Revista Brasileira de Estudos Pedagógicos. Brasília, v. 84, n. 206/207/208, p. 34-42, jan./dez. 2003. https://doi.org/10.24109/2176-6681.rbep.84i206-07-08.887

BESSA, Daniel. As Políticas Macroeconómicas do Post-25 de Abril - Ascenção e Declínio do Estado Social Português. Revista Crítica de Ciências Sociais, 15/16/17, 325-350, 1985.

BRASIL. Constituição da República Federativa do Brasil. 1988. Acesso: 02/07/2018. Disponível em http://www.planalto.gov.br/ccivil_03/constituicao/constituicaocompilado.htm BRASIL. Lei n. 9.394, de 20 de dezembro de 1996. Estabelece as diretrizes e bases da educação nacional. Diário Oficial da União, Brasília: 1996. 
BRASIL. Ministério da Educação. Secretaria de Educação Continuada, Alfabetização, Diversidade e Inclusão. Documento Nacional Preparatório à VI Conferência Internacional de Educação de Adultos / Versão atualizada Confintea Brasil+6. Brasília: MEC. Disponível em: <file:///C:/Users/Margarida/Desktop/2016/Forum\%20EJA/Confintea\%20+\%206/Pos\%20enco ntro\%20abril/documento_nacional.pdf>. 2016.

BRIGHT, Barry. The Epistemological Imperative. In Barry BRIGHT (ed.). Theory and Practice in the Study of Adult Education - The Epistemological Debate (pp. 1-12). London. Routledge, 1989. https://doi.org/10.4324/9780429436758-1

CARNEIRO, Roberto. (Ed.). Accreditation of prior learning as a lever for lifelong learning: Lessons learnt from the New Opportunities Initiative, Portugal. Braga: UNESCO/MENON Network/CEPCEP, Centro de Estudos dos Povos e Culturas de Expressão Portuguesa Universidade Católica Portuguesa, 2011.

CAVACO, C.; LAFONT, P.; PARIAT, M. Policies of adult education in Portugal and France: The European agenda of validation of non-formal and informal learning. International $\begin{array}{lllll}\text { Journal of Lifelong } & \text { Education, 33(3), 343-361, }\end{array}$ https://doi.org/10.1080/02601370.2014.896086

COSTA, Cláudia Borges; MACHADO, Maria Margarida. Políticas públicas e educação de jovens e adultos no Brasil. São Paulo: Cortez Editora. 2017.

DI PIERRO, M. C. Notas sobre a redefinição da identidade e das políticas públicas de educação de jovens e adultos no Brasil. Educ. Soc., Campinas, vol.26, nº 92, p.1115-1139, especial - Out. 2005. https://doi.org/10.1590/S0101-73302005000300018

DGEE. Educação de Adultos - Conceitos e Atividades Desenvolvidas. Lisboa: Ministério da Educação e Cultura/Direção-Geral de Extensão Educativa, 1991.

DGEP. Aspetos da Educação de Adultos em Portugal (Manuel Joaquim Sobral Gonçalves). Lisboa: Ministério da Educação e Cultura/Direção-Geral de Educação Permanente, 1978.

FAURE, E.; HERRERA, F.; KADDOURA, A.-R.; LOPES, H.; PETROVSKY, A. V.; RAHNEMA, M.; WARD, F. C. Learning to Be - The Word of Education Today and Tomorrow. Paris: UNESCO, 1972.

GRAMSCI, A. Cadernos do cárcere. Volume 3. Edição e Tradução de Carlos Nelson Coutinho; Coedição de Luiz Sérgio Henriques e Marco Aurélio Nogueira. Rio de Janeiro: Editora Civilização Brasileira. 2007.

HADDAD, Sérgio. A educação continuada e as políticas públicas no Brasil. REVEJ@ Revista de Educação de Jovens e Adultos, v. 1, n. 0, p. 27-38, ago. 2007.

IRELAND, Timothy. A EJA tem agora objetivos maiores que a alfabetização. Nova Escola. São Paulo. n. 223, p. 36 - 40, 2009.

IRELAND, Timothy; SPEZIA, Carlos Humberto (Orgs). Educação de Adultos em Retrospectiva: 60 anos de CONFINTEA. Brasília: UNESCO, MEC. 2012. 
LEMME, Paschoal. Memórias de um educador. 2ª ed. Vol. 5. Brasília: Inep, 2004.

LIMA, Licínio. Políticas de educação permanente: Qualificacionismo adaptativo ou educação de adultos? Sensus, 4(1), 105-121, 2014.

LIMA, Licínio. A Educação de Adultos em Portugal (1974-2004): Entre as Lógicas da Educação Popular e da Gestão de Recursos Humanos. In Rui CANÁRIO e Belmiro CABRITO (org.). Educação e Formação de Adultos - Mutações e Convergências, (pp. 3160). Lisboa: EDUCA-Formação, 2005.

LIMA, Licínio; ESTÊVÃO, Lucas; MATOS, Luís; MELO, Alberto; MENDONÇA, Amélia. Documentos Preparatórios III - Projetos de Reorganização do Subsistema de educação de Adultos. Lisboa: Comissão de reforma do Sistema Educativo/Ministério da Educação, 1988.

LIZ, C.; MACHADO, M.; BURNAY, E. Iniciativa novas oportunidades: Primeiros estudos da avaliação externa - Perceções sobre a iniciativa novas oportunidades (Caderno Temático $\mathrm{n}^{\circ}$ 2). Lisboa: Universidade Católica Portuguesa, 2009.

MACHADO, Maria Margarida. A educação de jovens e adultos no Brasil pós-Lei 9.394/96: a possibilidade de constituir-se como política pública. Em Aberto. v. 22, n. 82, p. 17-39, nov. Brasília: INEP. 2009.

MAGALHÃES, José. A Constituição e as suas Revisões, a Lei e a Justiça. In António Reis (coord.). Portugal 20 Anos de Democracia (115-135). Lisboa: Publicações Alfa, 1996.

MAGALHÃES, José. Dicionário da Revisão Constitucional. Lisboa: Editorial Notícias, 1999.

MARQUES, Marcelo. Finding and tracing the effects of governance processes in the new opportunities initiative: An outline. International Journal of Lifelong Education, 33(3), 290308, 2014. https://doi.org/10.1080/02601370.2014.896087

MOREIRA, Vítor. A Edificação do Novo Sistema Institucional Democrático. In António Reis (Dir.). Portugal Contemporâneo (1974-1992) (pp. 81-116). Lisboa: Publicações Alfa, 1992.

OLESEN, Hanning. Challenging Academia. In Maria Helena ANTUNES; Iolanda Costa GALINHA (orgs.), Wider Benefits of Learning: Understanding and Monitoring the Consequences of Adult Learning (pp. 30-35). Lisboa: Edições Universitárias Lusófonas, 2003.

PAIVA, Jane. Educação de Jovens e Adultos: Direito, Concepções e Sentidos. 2005.480 p. Tese (Doutorado em Educação) - Universidade Federal Fluminense. Niterói. 2005.

REIS, José (coord.). A Economia Política do Retrocesso. Crise, Causas e Objectivos. Coimbra: Almedina/CES, 2014.

SOUSA SANTOS, Boaventura. O Estado e a Sociedade em Portugal (1974-1988). Porto: Edições Afrontamento, 1990.

SANTOS SILVA, Augusto. Educação de Adultos - Educação Para o Desenvolvimento. Rio Tinto: Edições Asa/Clube do Professor, 1990. 
SANTOS SILVA, Augusto; ROTHES, Luís. Educação de Adultos. In A Evolução do Sistema Educativo e o PRODEP - Estudos Temáticos, Vol. III, (pp.17-111). Lisboa: Ministério da Educação, 1998.

STOCK, A. Lifelong Learning: Thirty Years of Educational Change. In: Peter RAGGATT; Richard EDWARDS; Nick SMALl (eds.), The Learning Society - Challenges and Trends (pp. 10-25). London: Routledge/The Open University, 1996.

STOER, Steven. Educação e Mudança Social em Portugal, 1970-1980: Uma Década de Transição. Porto: Edições Afrontamento, 1986.

TEIXEIRA, Anísio. Educação para a Democracia. Rio de Janeiro, José Olympio, 1936. 